\title{
An In Silico Study for the Identification of Novel Putative Compounds Against the Wild and Mutant Type Penicillin Bindling Protein 2 of Neisseria Gonorrhoeae
}

\author{
Vinod Kumar Yata ${ }^{1}$, Navamallika Dutta ${ }^{2(\mathbb{D})}$, Dorothy $\operatorname{Das}^{2(\mathbb{C})}$, \\ Venkata Satish Kumar Mattaparthi ${ }^{2}$ *(D) \\ 1 Animal Biotechnology Centre, National Dairy Research Institute, Karnal-132001, Haryana, India \\ 2 Molecular Modelling and Simulation Laboratory, Department of Molecular Biology and Biotechnology, Tezpur \\ University, Tezpur-784 028, Assam, India \\ * Correspondence: mvenkatasatishkumar@gmail.com, venkata@tezu.ernet.in;
}

Scopus Author ID 54962670000

Received: 21.7.2020; Revised: 23.08.2020; Accepted: 25.08.2020; Published: 30.08.2020

\begin{abstract}
Penicillin-binding protein 2 (PBP2) is an enzyme crucial for cell wall biosynthesis during cell proliferation of $N$. gonorrhoeae. In the present work, the crystal structures of wild and mutant type PBP2 were analyzed to identify structural changes leading to antibiotic resistance. Other than these two targets, three other targets were generated by analyzing possible hot spots for mutations in PBP2. By using a reverse screening approach, fifteen molecules were screened and processed for ligand binding analysis with all five targets. The analysis of the above studies suggested that two compounds Guanosine 5'-diphosphate and Thymidine 3', 5'-diphosphate show the good binding affinity than Ceftriaxone and other compounds. Further, we have generated ten novel compounds using Ceftriaxone, Guanosine 5'-diphosphate, and Thymidine 3', 5'-diphosphate. To identify the novel findings, all novel compounds were docked against aforesaid five targets. The studies resulted in the finding of three best molecules that may be considered as suitable, potent, and generic inhibitors against $N$. gonorrhoeae other than Ceftriaxone.
\end{abstract}

Keywords: Neisseria gonorrhoeae; Ceftriaxone; Hot spot wizard; CUPSAT; Chimera; Designing; Molecular Docking.

(c) 2020 by the authors. This article is an open-access article distributed under the terms and conditions of the Creative Commons Attribution (CC BY) license (https://creativecommons.org/licenses/by/4.0/).

\section{Introduction}

Penicillin-binding protein 2 (PBP2) is a membrane-bound enzyme involved in the process of synthesizing cross-linked peptidoglycan, which is a major component of $N$. gonorrhoeae cell wall [1]. The biosynthesis of the bacterial cell wall has been extensively studied as a potential antibiotic target since membrane-based efflux pump systems play an important role in bacterial pathogenicity and antibiotic resistance in bacteria [2]. Till today, three classes of PBPs have been identified in N. gonorrhoeae: Class A (PBP1) and Class B (PBP2), high molecular mass transpeptidases, and Class C (PBP3 \& PBP4), low molecular mass transpeptidases [3]. Previous studies have shown that Class $\mathrm{C}$ transpeptidases (PBP3 and PBP4) have a minor effect on the growth of the bacterium on deletion, whereas PBP1 \& PBP2 are essential for cell viability and therefore a fatal target for carbapenems and other $\beta$-lactam antibiotics [4]. $\beta$-lactam antibiotics show less minimum inhibitory concentration (MIC) against PBP2 than PBP1, which makes PBP2 a primary killing target to fight $N$. gonorrhoeae [5]. $\beta$ - 
lactam antibiotics are the structural mimics of the peptide substrate, and this is the reason behind their success against PBP2 [6].

The consistent increase in the prevalence of antibiotic-resistant strains of $N$. gonorrhoeae suggests that mutations may exist in PBP2 [7-9]. However, no mutations were found in the active site residues, whereby the function of the protein was intact, but mutations nearby active site residues may affect the binding interactions of PBP2 and $\beta$-lactam antibiotics [10]. PBP2 from $N$. gonorrhoeae is an appropriate system to understand antibiotic resistance because only a small number of mutations are responsible for conferring antibiotic resistance [11]. The rapid emergence of antibiotic-resistant strains [12-19] necessitates the urgency to find new drug molecules; those who can inhibit this pathogen in more efficient ways, in its native form, as well as mutant form. The need of the hour, in prevailing conditions, is, in silico approach, which has been very successful in discovering such desired or target drug molecules [20].

In the present study, wild and mutant type PBP2 of $N$. gonorrhoeae was chosen for the designing of putative novel compounds to overcome antibiotic resistance. By using a reverse screening approach, fifteen best molecules, similar to Ceftriaxone, were screened that may fit in the binding cavity of PBP2 efficiently. These molecules were further subjected to binding analysis with PBP2 by docking studies. Based on the docking results, ten novel putative compounds were designed and further docked against PBP2. Finally, we identified three potential novel compounds against the wild and mutant types of PBP2.

\section{Materials and Methods}

\subsection{Generation of mutant structures.}

The crystal structures of the wild and mutant type (here named as Mut, which has an insertion of aspartic acid before Asp ${ }^{346}$ ) of PBP2 of $N$. gonorrhoeae (PDB ID: 3EQU\& 3EQV, respectively) were taken from the PDB database (http://rcsb.org/pdb/home/home.do). Multiple sequence analysis (MSA) was performed to identify the position of binding site residues on the mutant type of PBP2 of $N$. gonorrhoeae. Identification of hot spots for mutation was made by utilizing HotSpot wizard (http://loschmidt.chemi.muni.cz/hotspotwizard), a tool for automatic identification of hot spot sites for the engineering of substrate specificity, activity or selectivity of enzymes. The strategy implemented in HotSpot wizard involves the targeting of functional residues located in highly variable positions to alter catalytic properties with reduced risk of losing catalytic activity. It enlists residues ordered by a suitable mutability score [21]. Protein stability upon single amino acid substitutions at the hotspot residues was measured using CUPSAT (http://cupsat.tu-bs.de), a computer program that combines structural information with statistically derived potentials to predict the changes in protein stability associated with amino acid mutations [22]. The stable mutants obtained can be chosen for further modeling studies. Finally, Chimera was used to mutating the residues (using a rotamer tool) at the hotspot sites [23]. The best possible substitution was finalized using the probability of the existence of a particular substitution. To remove the bad contacts from the generated mutant structures, the energy minimization of all the mutants were also undertaken.One hundred steepest descent steps were used with ten conjugate gradient steps for energy minimization. All other parameters were kept on default. 


\subsection{Drug screening.}

To find out potent lead compounds against PBP2 that could have some similar properties to the only available drug (at the present time) ceftriaxone, its three-dimensional structure was submitted to PharmMapper (http://59.78.96.61/pharmmapper). PharmMapper is an open-source platform that uses the approach of 'reverse' pharmacophore mapping [24] in order to predict the potential drug targets against any given small molecule. It predicts the best mapping for a given query molecule against all the pharmacophore models in PharmTargetDB using the ligand-protein reverse docking approach [25]. Later, around 300 targets were annotated with their respective aligned poses. The complexes of all the three hundred targets were further evaluated to enlist the putative ligand molecules, which have some similarity with Ceftriaxone. Now, these ligands were further submitted to PharmaGist (http://bioinfo3d.cs.tau.ac.il/PharmaGist) to find out the best pharmacophore models considering Ceftriaxone as a pivot molecule. This server is based on the deterministic pharmacophore detection method [26,27].

\subsection{Drug designing.}

Ceftriaxone and best-screened molecules have been edited to design novel ligand molecules with the help of ChemSketch. ChemSketch is a molecular modeling program used to create and modify the chemical structure in two and three dimensions with a better understanding of chemical bonds and functional groups [28]. Avogadro is an advanced molecule editor designed for the cross-platform and also can help to find out the best stable structure by energy minimization [29].

\subsection{Molecular docking analysis.}

Molecular docking of all the screened, designed ligands and wild, mutant type PBP2 was carried out using Autodock4.2 software package from The Scripps Research Institute [30]. Initially, all the receptors and ligands are made to undergo a pre-optimization process using the autodock parameters like atom types, torsion modes, and partial charges. It predicts the bound conformations of a small, flexible ligand to a nonflexible macromolecular target of known structure. A grid box of the size $42 \times 52 \times 42$ points covering the binding site residues was used throughout all the docking analysis. A grid spacing of $0.422 \AA$ was used to ensure the standard grid spacing around the binding site. Lamarckian Genetic algorithm (LGA) was applied to find out the most favorable interactions. During each docking experiment, 100 runs were carried out, and ten experiments were carried out for each ligand. The confirmation with the most favorable free energy of binding and the lowest root mean square deviation (RMSD) was selected.

\section{Results and Discussion}

In this study, initially, the crystal structures of both wild and mutant (Mut) type of PBP2 of $N$. gonorrhoeae were analyzed. All the PBPs, including PBP2 contain two domains, an Nterminal domain and a C-terminal TPase (or penicillin-binding) domain. PBP2 active site is comprised of three conserved sequence motifs that are observed in nearly all the betalactamases. From the previous studies, the $\mathrm{S} X X \mathrm{~K}$ motif is located at the $\mathrm{N}$-terminal end of helix $\alpha 2$ and contains two residues that are important for catalysis: $\mathrm{Ser}^{310}$ and $\mathrm{Lys}^{313}$. The SXN motif, 
comprising $\mathrm{Ser}^{362}, \mathrm{Ser}^{363}, \mathrm{Asn}^{364}$, is present on the loop connecting $\alpha 4$ and $\alpha 5$. The KTG motif, comprising Lys $^{497}$, Thr ${ }^{498}$, and Gly ${ }^{499}$, is located on strand $\beta 3$ [11,31,32]. Analysis of both wild and mutant type PBP2 structure suggests that the insertion of an aspartic acid before the $\mathrm{Asp}^{346}$ leads to the change in the hydrogen bonding interaction between $\operatorname{Ser}^{363}$ and $\mathrm{Asp}^{346}$ (hydrogen bond length changes from $3.19 \AA$ to $3.41 \AA$ for wild and mutant type PBP2 respectively), further decreasing the vicinity of binding cavity. When the measurements were taken with the consecutive residues, it was found that $\operatorname{Ser}^{363}$ slightly moves inside towards Asn ${ }^{364}$ leading to the decreasing the size of the binding pocket and the reactivity of the enzyme for $\beta$-lactam antibiotics without significantly affecting the ability of the enzyme to catalyze transpeptidation of its natural peptide surface (Figure 1).

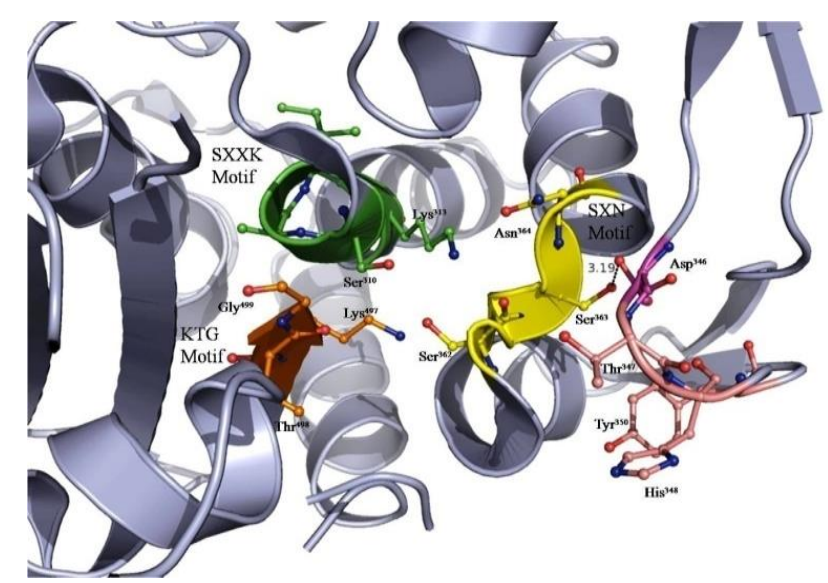

Figure 1. The binding site of the PBP2 from N. gonorrhoeae is shown. In green, it shows SXXK motif, SXN motif in yellow and KTG motif in orange. All the seven binding residues: Ser310, Lys313, Ser362, Asn364, Lys497, Thr498, and Gly499, are labeled. In pink Asp346 is shown, site of the mutation that makes a hydrogen bond with the middle residue of the SXN motif (mostly Ser363). In light pink, a hot spot found for the mutations is shown.

Identifying the amino acid for mutagenesis is challenging, and any clue from in silico analysis greatly reduces the experimental work. So, here an attempt was made to find out the hot spots for the mutations in PBP2. Three residues were found with a considerable mutability score. $\mathrm{Thr}^{347}$ had the highest mutability score of nine, followed by $\mathrm{Tyr}^{350}$ and $\mathrm{His}^{348}$ with a mutability score of seven and six, respectively. An amino acid for mutation at a hot spot residue was selected on the basis of its stability (thermal and denaturant) in the protein after the mutation and the probability of existence. For $\mathrm{Thr}^{347}$, Tyr had the highest probability of the existence of $53 \%$, whereas, for $\mathrm{Tyr}^{350}$ and $\mathrm{His}^{348}$, Phe (51\%) and Cys (81\%) were selected with the highest probability of existence, respectively. So, three mutants were generated with the point mutations of ( $\mathrm{Thr}^{347}-\mathrm{Ty}$, $\mathrm{Tyr}^{350}$-Phe, and $\mathrm{His}^{348}$-Cys) near the vicinity of the active site. All three mutations lower the bond length between $\mathrm{Ser}^{363}$ and Asp ${ }^{346}$, suggesting that these mutations lead to an increase in the size of the binding cavity that further supports the binding results of the ligand molecules with these three mutant structures (Table 1).

Ceftriaxone, a third-generation cephalosporin antibiotic, is the only potent drug left for gonorrhea infections due to antibiotic resistance. So, in order to screen other possible ligand molecules, the three-dimensional structure of Ceftriaxone was submitted to PharmMapper. It has annotated 300 possible protein targets for Ceftriaxone, which were further processed to remove redundancy. As many as 198 targets were found with unique PDB ID, and analyzed to get the ligands with similar activity to Ceftriaxone. After analyzing the above, 117 unique ligands were found and were further submitted in PharmaGist in twelve sets. PharmaGist listed 
all 117 molecules according to their score and best pharmacophore structure. A cutoff score of 60.696 of best pairwise alignments was set, which yielded around fifteen potential ligand molecules. The score of a pairwise alignment signified the weighted sum of the matched pivot features.

Table 1. Summary of Binding results of the ligand molecules with the three mutant structures (Thr347-Tyr, Tyr350-Phe, and His348-Cys).

\begin{tabular}{|c|c|c|c|c|c|c|}
\hline \multirow[t]{2}{*}{ Sr no } & \multirow{2}{*}{$\begin{array}{c}\text { Hotspot } \\
\text { amino acid }\end{array}$} & \multirow{2}{*}{$\begin{array}{c}\text { Mutabilit } \\
\text { y Score }\end{array}$} & \multicolumn{2}{|c|}{ Stabilizing amino acids } & \multicolumn{2}{|c|}{ Destabilizing amino acids } \\
\hline & & & Thermal & Denaturants & Thermal & Denaturants \\
\hline 1. & $\mathrm{Thr}^{347}$ & $\begin{array}{c}9 \\
\text { (high) }\end{array}$ & Trp,Tyr, Cys & $\begin{array}{c}\text { Ala, Val, Leu, Met, } \\
\text { Pro, Ser, Phe, Tyr, His }\end{array}$ & $\begin{array}{l}\text { Gly, Ala, Val, Leu, } \\
\text { Ile, Met, Pro, Ser, } \\
\text { Phe, Gln, Lys, Asn, } \\
\text { Glu, Asp, Arg, His }\end{array}$ & $\begin{array}{c}\text { Gly, Ile, Trp, Gln, } \\
\text { Lys, Asn, Glu, Asp, } \\
\text { Arg, Cys }\end{array}$ \\
\hline 2. & $\mathrm{Tyr}^{350}$ & $\begin{array}{c}7 \\
\text { (high) }\end{array}$ & Phe, His & $\begin{array}{l}\text { Gly, Ala, Val, Leu, Ile, } \\
\text { Met, Pro, Trp, Thr, } \\
\text { Phe, Gln, Lys, Asn, } \\
\text { Cys, Asp, Arg, His }\end{array}$ & $\begin{array}{l}\text { Gly, Ala, Val, Leu, } \\
\text { Ile, Met, Pro, Trp, } \\
\text { Ser, Thr, Gln, Lys, } \\
\text { Asn, Cys, Glu, Asp, } \\
\text { Arg }\end{array}$ & Ser, Glu \\
\hline 3. & His $^{348}$ & $\begin{array}{c}6 \\
\text { (average) }\end{array}$ & $\begin{array}{l}\text { Gly, Leu, Ile, } \\
\text { Met, Ser, Thr, } \\
\text { Cys }\end{array}$ & $\begin{array}{c}\text { Gly, Ala, Val, Leu, Ile, } \\
\text { Met, Pro, Ser, Thr, Gln, } \\
\text { Lys, Cys, Glu, Asp, } \\
\text { Arg }\end{array}$ & $\begin{array}{l}\text { Ala, Val, Pro, Trp, } \\
\text { Phe, Gln, Lys, Asn, } \\
\text { Glu, Asp, Arg, Tyr }\end{array}$ & Trp, Phe, Tyr, Asn \\
\hline
\end{tabular}

Thereafter, molecular docking studies were performed on Ceftriaxone and the fifteen screened compounds with PBP2 (wild and mutant) of N. gonorrhoeae. Eighty sets of partial mono flexible protein-ligand docking were established to screen the best compounds that show a comparatively low binding energy than the Ceftriaxone at a standard RMSD ( $0 \AA)$.

Ceftriaxone has shown a good binding affinity with all the targets except Mut. This is because Mut has the natural mutation, an Asp, inserted before $\mathrm{Asp}^{346}$ that leads to decreased binding affinity with a very significant increase in $\mathrm{IC}_{50}(0.40$ to $590.81 \mu \mathrm{M})$ compared to wild type PBP2. In Mut ${ }^{1}$, replacing $\mathrm{Thr}^{347}$ with Tyr, enables the amino group of Tyr to come inside the binding cavity and interact with the amino group of the thiazole ring of Ceftriaxone by hydrogen bonding, which increases the binding affinity. In Mut ${ }^{2}$, replacing $\mathrm{Tyr}^{350}$ with Phe increase the binding affinity of the substrate due to a slight increase in the volume of the binding cavity as Phe lacks the hydroxyl group as compared to Tyr. In Mut ${ }^{3}$, replacing His ${ }^{348}$ with Cys, the sulfur molecule present in Cys_increases the binding affinity of the substrate to fit efficiently within the proximity of the binding cavity (Figure 2).

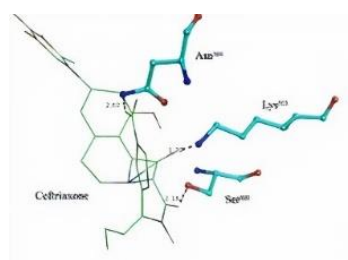

(a)

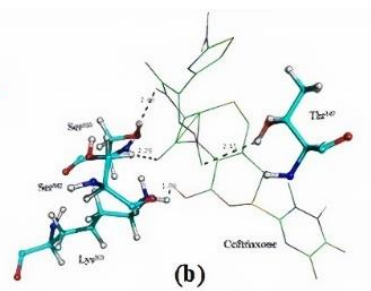

(b)

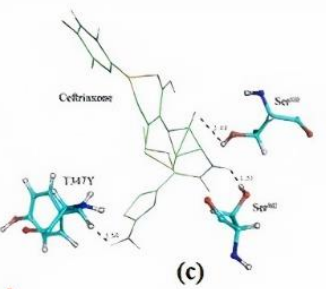

(c)

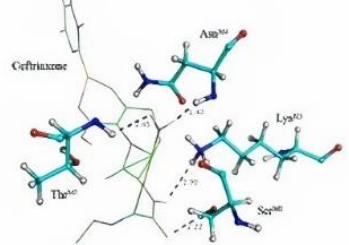

(d)

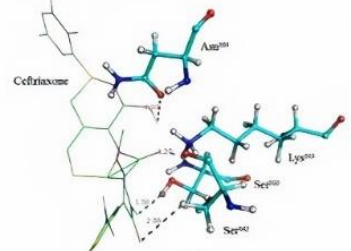

(e)

Figure 2. Binding complexes of Ceftriaxone with all the five targets have shown: (a) Ceftriaxone and wild type PBP2, (b) Ceftriaxone and Mut, (c) Ceftriaxone and Mut1, (d) Ceftriaxone and Mut2, (e) Ceftriaxone and Mut3. 
Guanosine 5'-diphosphate displayed a very good binding affinity with the natural as well as mutants of PBP2 (except Mut ${ }^{1}$ ), as compared to the Ceftriaxone and other ligand molecules. Interaction studies of Guanosine 5'-diphosphate with all the targets can explain the decreased binding affinity with Mut1. As residue $\mathrm{Thr}^{347}$ also interacts with the substrate, in the case of Guanosine 5'-diphosphate, it was deciphered that, generally, both the hydroxyl groups attached with ribose sugar interact with the carboxyl group of $\mathrm{Thr}^{347}$, providing good interactions in the binding cavity. When $\mathrm{Thr}^{347}$ was replaced by Tyr, the only interaction was found between the oxygen molecule of purine ring of Guanosine 5'-diphosphate and the amino group of Tyr, leading to a less interacting Guanosine 5'-diphosphatein the binding cavity. Whereas, Thymidine 3', 5'-diphosphate showed a good binding affinity with Mut ${ }^{1}$. Interaction between a hydroxyl group of the pyrimidine ring of Thymidine 3', 5'-diphosphate and amino group of Tyr, increased the possibility of favorable interactions, and so the binding affinity with Mut $^{1}$ (Table 2).

Table 2. Binding analysis of the fifteen potential ligand molecules against PBP2 (wild and mutant) of $N$. gonorrhoeae.

\begin{tabular}{|c|c|c|c|c|c|c|c|c|c|c|c|}
\hline \multirow{2}{*}{$\begin{array}{l}\text { Sr } \\
\text { no }\end{array}$} & \multirow[t]{2}{*}{ Molecule name } & \multicolumn{5}{|c|}{ Binding Energies (kcal/mol) } & \multicolumn{5}{|c|}{ Inhibitory Constant $(\boldsymbol{\mu M})$} \\
\hline & & $\begin{array}{l}\text { PBP2 } \\
\text { Wild } \\
\text { type }\end{array}$ & Mut & $\begin{array}{l}\text { Mut1 } \\
\text { T347Y }\end{array}$ & $\begin{array}{l}\text { Mut2 } \\
\text { Y350F }\end{array}$ & $\begin{array}{l}\text { Mut3 } \\
\text { H348C }\end{array}$ & $\begin{array}{l}\text { PBP2 } \\
\text { Wild type }\end{array}$ & Mut & $\begin{array}{l}\text { Mut1 } \\
\text { T347Y }\end{array}$ & $\begin{array}{l}\text { Mut2 } \\
\text { Y350F }\end{array}$ & $\begin{array}{l}\text { Mut3 } \\
\text { H348C }\end{array}$ \\
\hline 1. & Ceftriaxone & -4.63 & -4.40 & -4.72 & -5.05 & -8.67 & 0.40 & 590.81 & 344.73 & 198.46 & 0.44 \\
\hline 2. & $\begin{array}{l}\text { 5adenylylbeta,ga } \\
\text { mma- } \\
\text { methylenediphosp } \\
\text { honate }\end{array}$ & -8.32 & -8.17 & -7.45 & -7.59 & -9.99 & 0.00080 & 1.02 & 3.46 & 2.73 & 0.047 \\
\hline 3. & 5-iodouracil & -8.76 & -6.43 & -9.17 & -6.86 & -8.22 & 0.00038 & 19.3 & 0.19 & 9.41 & 0.95 \\
\hline 4. & $\begin{array}{l}\text { 17-desmethoxy- } \\
17-n, n- \\
\text { dimethylaminoeth } \\
\text { ylamino- } \\
\text { geldanamycin }\end{array}$ & -7.30 & -6.55 & -7.41 & -5.1 & -8.92 & 0.0044 & 15.83 & 3.71 & 181.99 & 0.29 \\
\hline 5. & $\begin{array}{l}\text { 5guanosinediphos } \\
\text { phate- } \\
\text { monothiophosphat } \\
\text { e }\end{array}$ & -8.55 & -6.49 & -7.15 & -4.13 & -9.65 & 0.00053 & 17.59 & 5.74 & 941.64 & 0.084 \\
\hline 6. & $\begin{array}{l}\text { Flavin } \\
\text { mononucleotide }\end{array}$ & -6.16 & -8.53 & -6.58 & -10.29 & -11.08 & 0.030 & 0.6 & 14.98 & 0.028 & 0.007 \\
\hline 7. & $\begin{array}{l}\text { 6,7-dimethyl-8- } \\
\text { ribityllumazine }\end{array}$ & -6.96 & -6.77 & -7.56 & -2.79 & -10.31 & 0.0079 & 10.89 & 2.87 & 896 & 0.028 \\
\hline 8. & $\begin{array}{l}\text { 6,7-oxo- } 8,7,8- \\
\text { dihydropteridine- } \\
\text { 2,4-dione }\end{array}$ & -7.0 & -8.13 & -6.61 & -4.12 & -10.39 & 0.00744 & 1.09 & 14.28 & 961.22 & 0.024 \\
\hline 9. & $\begin{array}{l}\text { Guanosine-3'- } \\
\text { monophosphate }\end{array}$ & -5.24 & -6.47 & -7.61 & -7.34 & -9.25 & 0.144 & 17.98 & 2.63 & 4.17 & 0.16 \\
\hline 10. & $\begin{array}{l}\text { Inosine } \\
\text { monophosphate }\end{array}$ & -6.27 & -6.77 & -6.48 & -6.21 & -8.58 & 0.025 & 10.98 & 17.94 & 28.25 & 0.51 \\
\hline 11. & $\begin{array}{l}\text { N,o-didansyl-1- } \\
\text { tyrosine }\end{array}$ & -6.87 & -6.99 & -4.27 & -5.81 & -8.9 & 0.0092 & 7.53 & 741.04 & 55.39 & 0.3 \\
\hline 12. & $\begin{array}{l}\text { Pyridoxamine } \\
\text { phosphate }\end{array}$ & -5.22 & -6.14 & -6.33 & -5.69 & -8.27 & 0.150 & 31.66 & 23.0 & 67.3 & 0.86 \\
\hline 13. & $\begin{array}{l}\text { Adenosine } \\
\text { triphosphate }\end{array}$ & -7.96 & -10.08 & -8.31 & -9.2 & -11.15 & 2.62 & 0.01 & 0.81 & 0.18 & 0.067 \\
\hline 14. & $\begin{array}{l}\text { Thymidine-3',5'- } \\
\text { diphosphate }\end{array}$ & -8.35 & -8.38 & -9.54 & -8.38 & -12.97 & 0.00105 & 0.72 & 0.1 & 0.72 & 0.0003 \\
\hline 15. & $\begin{array}{ll}\text { Guanosine } & \text { 5'- } \\
\text { diphosphate }\end{array}$ & -9.52 & -10.89 & -8.73 & -11.25 & -13.89 & 0.00758 & 0.04 & 0.4 & 0.0057 & 0.000075 \\
\hline 16. & $\begin{array}{l}\text { Guanylyl-imido- } \\
\text { diphosphate }\end{array}$ & -8.33 & -7.48 & -8.5 & -4.98 & -13.63 & 0.00785 & 3.28 & 0.58 & 224.72 & 0.0001 \\
\hline
\end{tabular}

When the interactions of Ceftriaxone with PBP2 were analyzed, it was found that it makes three hydrogen bonds with binding site residues. The amino group of the thiazole ring interacts with the amino group of $\mathrm{Asn}^{364}$ with a bond length of $2.59 \AA$. Another two hydrogen bonds are formed by the amide group and oxygen molecule attached to the $\beta$-lactam ring with 
the hydroxyl groups of $\mathrm{Ser}^{362}$ and $\mathrm{Ser}^{310}$, respectively. These bonds are shorter in length (1.91 $\AA$ and $1.68 \AA$, respectively), keeping the $\beta$-lactam ring as the most interacting part of Ceftriaxone. Ceftriaxone was edited by keeping the $\beta$-lactam ring as a seed molecule and taking the best-screened compounds (Guanosine 5'-diphosphate and Thymidine-3', 5'-diphosphate) to generate ten novel compounds. The molecular formula and the structures of all ten molecules are shown in Table 3.

Table 3. Molecular details of the ten generated novel compounds obtained by editing Ceftriaxone.

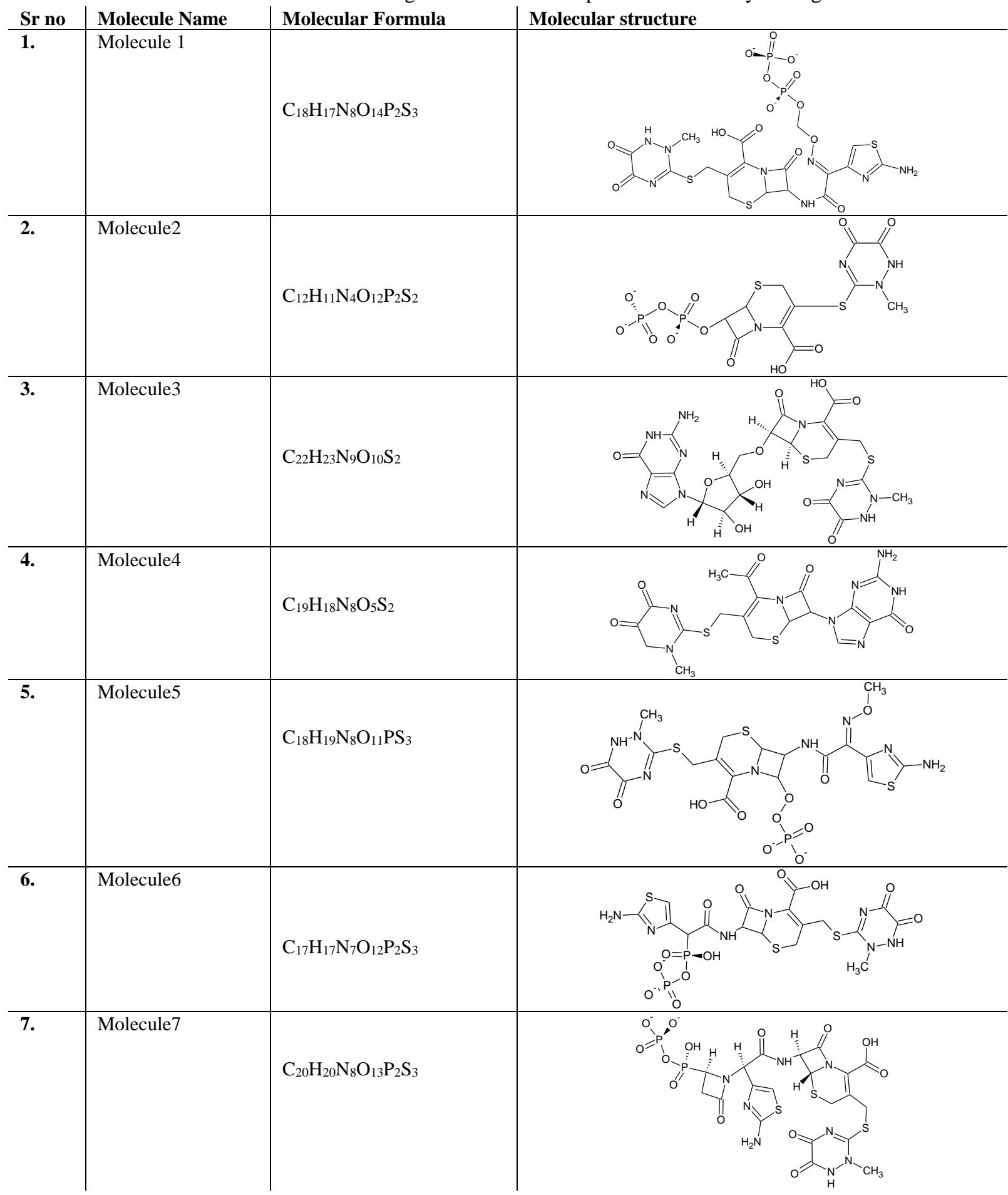




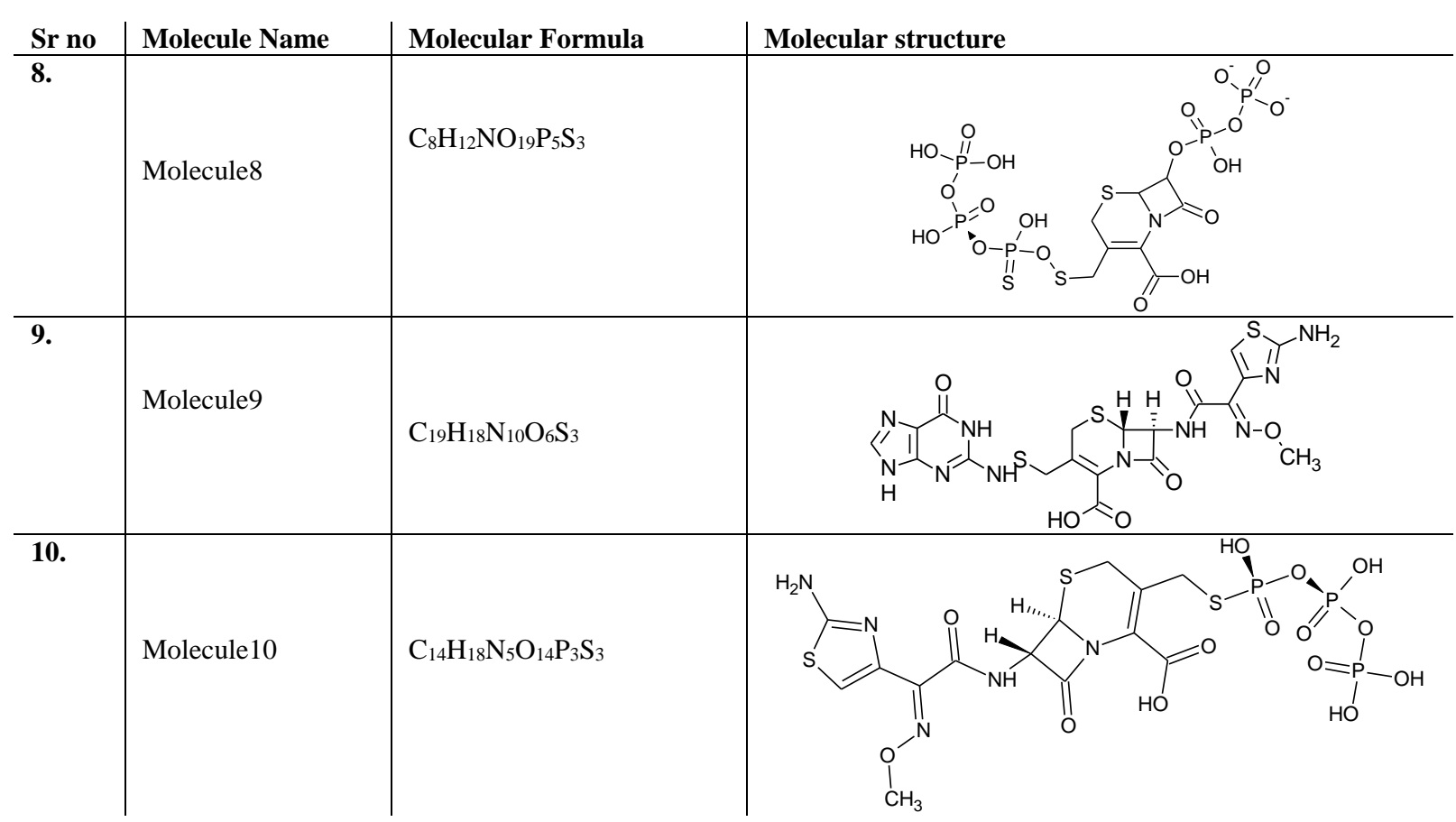

After energy minimization, all the ten compounds were processed for binding analysis against all the five targets keeping the same parameters as above. Here fifty docking sets were settled, and the results are shown in Table 4.

Table 4. Binding analysis of the ten novel compounds against PBP2 (wild and mutant) of N. gonorrhoeae.

\begin{tabular}{|c|c|c|c|c|c|c|c|c|c|c|c|}
\hline \multirow{2}{*}{$\begin{array}{l}\text { Sr } \\
\text { no }\end{array}$} & \multirow{2}{*}{$\begin{array}{l}\text { Molecule } \\
\text { name }\end{array}$} & \multicolumn{5}{|c|}{ Binding Energies (kcal/mol) } & \multicolumn{5}{|c|}{ Inhibitory Constant $(\boldsymbol{\mu M})$} \\
\hline & & $\begin{array}{c}\text { PBP2 } \\
\text { Wild type }\end{array}$ & Mut & $\begin{array}{c}\text { Mut1 } \\
\text { T347Y }\end{array}$ & $\begin{array}{c}\text { Mut2 } \\
\text { Y350F }\end{array}$ & $\begin{array}{c}\text { Mut3 } \\
\text { H348C }\end{array}$ & $\begin{array}{c}\text { PBP2 } \\
\text { Wild type }\end{array}$ & Mut & $\begin{array}{l}\text { Mut1 } \\
\text { T347Y }\end{array}$ & $\begin{array}{c}\text { Mut2 } \\
\text { Y350F }\end{array}$ & $\begin{array}{c}\text { Mut3 } \\
\text { H348C }\end{array}$ \\
\hline 1. & Molecule 1 & -7.05 & -6.55 & -6.42 & -1.56 & -0.082 & -6.81 & 30.99 & 19.53 & 958.39 & 1268.32 \\
\hline 2. & Molecule2 & -6.81 & -9.38 & -10.15 & -10.8 & -8.63 & -6.02 & 0.112 & 0.036 & 0.012 & 0.47 \\
\hline 3. & Molecule3 & -4.26 & -6.93 & -10.41 & -7.51 & -5.81 & -5.16 & 8.37 & 0.023 & 3.11 & 55.54 \\
\hline 4. & Molecule4 & -6.02 & -11.34 & -10.06 & -11.8 & -8.77 & -6.06 & 0.008 & 0.042 & 0.002 & 0.96 \\
\hline 5. & Molecule5 & -5.3 & -8.69 & -8.23 & -10.25 & -8.21 & -5.75 & 0.427 & 0.92 & 0.030 & 0.37 \\
\hline 6. & Molecule6 & -5.16 & -7.29 & -5.93 & -6.25 & -5.27 & 10.13 & 4.89 & 45.23 & 16.76 & 136.1 \\
\hline 7. & Molecule7 & -0.06 & -8.58 & -0.84 & -0.02 & -6.9 & 35.2 & 0.515 & 1003.53 & 1594.09 & 8.74 \\
\hline 8. & Molecule8 & -6.06 & -6.11 & -4.38 & -3.6 & -3.96 & 165.96 & 33.26 & 853.96 & 2280 & 1250 \\
\hline 9. & Molecule9 & -9.58 & -11.02 & -7.83 & -7.64 & -6.9 & 36.03 & 0.008 & 1.82 & 2.53 & 8.71 \\
\hline 10. & Molecule10 & -5.75 & -7.89 & -8.41 & -6.88 & -6.16 & 61.41 & 1.65 & 0.69 & 9.13 & 30.47 \\
\hline
\end{tabular}

The analysis indicated that PBP2- Molecule 9, Mut- Molecule 4, Mut ${ }^{1}$ - Molecule 3, $\mathrm{Mut}^{2}$ - Molecule 4, and $\mathrm{Mut}^{3}$ - Molecule 4complexes have very less binding energy as compared to Ceftriaxone and other designed molecules, respectively.

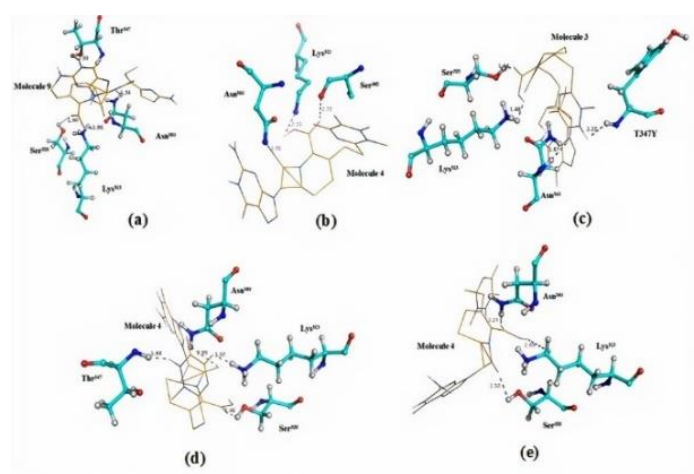

Figure 3. Binding interactions between the complexes are shown in the stick-ball and wire form: (a) Molecule 9 and wild type PBP2, (b) Molecule 4 and Mut, (c) Molecule 3 and Mut1, (d) Molecule 4 and Mut2, (e) Molecule 4 and Mut3. 
According to Figure 3(a), in Molecule 9, replacing the triazine ring with guanine results in close packing of the molecule in the binding moiety and also, leads to a new interaction between $\mathrm{Thr}^{347}$ and C-2 amino group of the guanine with a bond length of $2.98 \AA$ A. Molecule 4 has shown the best binding affinity with Mut, Mut ${ }^{2}$ and Mut $^{3}$. As shown in Figure 3(b), 3(d), and 3(e), Molecule 4 displayed very close interactions with the binding site residues due to its reduced size compared to Ceftriaxone, as guanine has been directly attached to the $\beta$-lactam ring. Again, reduced binding affinity was analyzed for Molecule 4 and Mut ${ }^{1}$ because of T347Y mutation, causing loss of the important interaction for the binding, between the amino group of triazine ring and the amino group of $\mathrm{Thr}^{347}$. Putative ligand binding studies of Molecule 3 with Mut ${ }^{1}$ shows a subtle change in the binding affinity as compared to Molecule 4 ( -10.06 to $-10.41 \mathrm{kcal} / \mathrm{mol}$ ), which can be accounted to the interaction of an amino group of triazine ring and the amino group of mutated Tyr residue Figure 3(c).

\section{Conclusions}

In this study, we have chosen wild and mutant type PBP2 to find out novel compounds to encounter $N$. gonorrhoeae. Fifteen molecules that may fit in the active site of the PBP2 were shortlisted and processed for binding analyses. Based on the binding analyses, two compounds Guanosine 5'-diphosphate and Thymidine 3', 5'-diphosphate were selected, eliciting a better binding affinity among the fifteen compounds as well as lesser binding energy than the Ceftriaxone. Ten novel compounds were generated using ceftriaxone skeleton and aforesaid two novel compounds. In silico analyses also revealed Molecule 3, Molecule 4, and Molecule 9 as potential drug molecules, which show higher binding affinity. These compounds are promising and could significantly block the activities of wild and mutant types of PBP2 of $N$. gonorrhoeae and provide a rationale for therapeutic intervention in the future.

\section{Funding}

This research received no external funding.

\section{Acknowledgments}

We would like to thank the Tezpur University and UGC, India for the start-up grant and DBT funded Bioinformatics Infrastructure facility in the Department of Molecular Biology and Biotechnology at Tezpur University for providing us computational facility to carry out this research work.

\section{Conflicts of Interest}

The authors declare no conflict of interest.

\section{References}

1. Ameyama, S.; Onodera, S.; Takahata, M.; Minami, S.; Maki, N.; Endo, K.; Goto, H.; Suzuki, H.; Oishi, Y. Mosaic-like structure of penicillin-binding protein 2 Gene (penA) in clinical isolates of Neisseria gonorrhoeae with reduced susceptibility to cefixime. Antimicrob Agents Chemother 2002, 46, 3744-3749, https://doi.org/10.1128/AAC.46.12.3744-3749.2002.

2. Kaatz, G.W. Inhibition of bacterial efflux pumps: a new strategy to combat increasing antimicrobial agent resistance. Expert Opin Emerg Drugs 2002, 7, 223-233, https://doi.org/10.1517/14728214.7.2.223.

3. Stefanova, M.E.; Tomberg, J.; Olesky, M.; Holtje, J.V.; Gutheil, W.G.; Nicholas, R.A. Neisseria gonorrhoeae penicillin-binding protein 3 exhibits exceptionally high carboxypeptidase and beta-lactam binding activities. Biochemistry 2003, 42, 14614-14625, https://doi.org/10.1021/bi0350607. 
4. Tomberg, J.; Unemo, M.; Davies, C.; Nicholas, R.A. Molecular and structural analysis of mosaic variants of penicillin-binding protein 2 conferring decreased susceptibility to expanded-spectrum cephalosporins in Neisseria gonorrhoeae: role of epistatic mutations. Biochemistry 2010, 49, 8062-8070, https://doi.org/10.1021/bi101167x.

5. Thakur, S.D.; Starnino, S.; Horsman, G.B.; Levett, P.N.; Dillon, J.R. Unique combined penA/mtrR/porB mutations and NG-MAST strain types associated with ceftriaxone and cefixime MIC increases in a 'susceptible' Neisseria gonorrhoeae population. J Antimicrob Chemother 2014, 69, 1510-1516, https://doi.org/10.1093/jac/dkt543

6. Lee, M.; Hesek, D.; Suvorov, M.; Lee, W.; Vakulenko, S.; Mobashery, S. A mechanism-based inhibitor targeting the DD-transpeptidase activity of bacterial penicillin-binding proteins. J Am Chem Soc 2003, 125, 16322-16326, https://doi.org/10.1021/ja0384451.

7. Singh, A.;Turner, J. M.; Tomberg, J.; Fedarovich, A.; Unemo, M.; Nicholas, R. A.; Davies, C. Mutations in penicillin-binding protein 2 from cephalosporin-resistant Neisseria gonorrhoeae hinder ceftriaxone acylation by restricting protein dynamics. J. Biol Chem. 2020, 295, 7529-7543, https://doi.org/10.1074/jbc.ra120.012617

8. Młynarczyk-Bonikowska, B.; Majewska, A.; Malejczyk, M.; Młynarczyk, G.; Majewski, S. Multiresistant Neisseria gonorrhoeae: a new threat in second decade of the XXI century. Med. Microbiol. Immunol. 2020, 209, 95-108, https://doi.org/10.1007/s00430-019-00651-4.

9. Shaskolskiy, B.; Dementieva, E.; Kandinov, I.; Filippova, M.; Petrova, N.; Plakhova, X.; Chestkov, A.; Kubanov, A. Resistance of Neisseria gonorrhoeae isolates to beta-lactam antibiotics (benzylpenicillin and Ceftriaxone) in Russia, 2015-2017. PLoS ONE 2019, 14, https://doi.org/10.1371/journal.pone.0220339.

10. Fedarovich, A.; Cook, E.; Tomberg, J.; Nicholas, R.A.; Davies, C. Structural effect of the Asp345a insertion in penicillin-binding protein 2 from penicillin-resistant strains of Neisseria gonorrhoeae. Biochemistry 2014, 53, 7596-7603, https://doi.org/10.1021/bi5011317.

11. Powell, A.J.; Tomberg, J.; Deacon, A.M.; Nicholas, R.A.; Davies, C. Crystal structures of penicillin-binding protein 2 from penicillin-susceptible and -resistant strains of Neisseria gonorrhoeae reveal an unexpectedly subtle mechanism for antibiotic resistance. $J$ Biol Chem 2009, 284, 1202-1212, https://doi.org/10.1074/jbc.M805761200

12. Peterson, E.; Kaur, P. Antibiotic Resistance Mechanisms in Bacteria: Relationships Between Resistance Determinants of Antibiotic Producers, Environmental Bacteria, and Clinical Pathogens. Front Microbiol 2018, 9, https://doi.org/10.3389/fmicb.2018.02928

13. Ogawara, H. Comparison of Antibiotic Resistance Mechanisms in Antibiotic-Producing and Pathogenic Bacteria. Molecules 2019, 19, https://doi.org/10.3390/molecules24193430

14. Wencewicz, TA. Crossroads of Antibiotic Resistance and Biosynthesis. J Mol Biol 2019, 431, 3370-3399, https://doi.org/10.1016/j.jmb.2019.06.033.

15. Catherine, L.T.; Philip, H.; Eilis, C.B.; Charlotte, K.C.; Viivi, H.A.H.; Yuiko,T.; James, S. $\beta$-Lactamases and $\beta$-Lactamase Inhibitors in the 21st Century. $J$ Mol Biol 2019, 431, 3472-3500, https://doi.org/10.1016/j.jmb.2019.04.002.

16. Singh, A.; Tomberg, J.; Nicholas, R.A.; Davies, C.; Recognition of the $\beta$-lactam carboxylate triggers acylation of Neisseria gonorrhoeae penicillin-binding protein 2. J. Biol Chem. 2019, 294, 14020-14032, https://doi.org/10.1074/jbc.ra119.009942.

17. Malik, B.; Bhattacharyya, S. Antibiotic drug-resistance as a complex system driven by socio-economic growth and antibiotic misuse. Sci Rep 2019, 9, https://doi.org/10.1038/s41598-019-46078-y.

18. Mark, L.; Ali, S.; Khondaker, M.R. Antibiotic resistance breakers: current approaches and future directions. FEMS Microbiol. Rev. 2019, 43, 490-516, https://doi.org/10.1093/femsre/fuz014.

19. Tyers, M.; Wright, G.D. Drug combinations: a strategy to extend the life of antibiotics in the 21 st century. Nat Rev Microbiol 2019, 17, 141-155, https://doi.org/10.1038/s41579-018-0141-x.

20. Vidal, D.; Garcia-Serna, R.; Mestres, J. Ligand-based approaches to in silico pharmacology. Methods Mol Biol 2011, 672, 489-502, https://doi.org/10.1007/978-1-60761-839-3_19

21. Pavelka, A.; Chovancova, E.; Damborsky, J. HotSpot Wizard: a web server for identification of hot spots in protein engineering. Nucleic Acids Res 2009, 37, W376-383, https://doi.org/10.1093/nar/gkp410

22. Parthiban, V.; Gromiha, M.M.; Schomburg, D. CUPSAT: prediction of protein stability upon point mutations. Nucleic Acids Res 2006, 34, W239-242, https://doi.org/10.1093/nar/gk1190.

23. Pettersen, E.F.; Goddard, T.D.; Huang, C.C.; Couch, G.S.; Greenblatt, D.M.; Meng, E.C.; Ferrin, T.E. UCSF Chimera--a visualization system for exploratory research and analysis. J Comput Chem 2004, 25, 1605-1612, https://doi.org/10.1002/jcc.20084.

24. Liu, X.; Ouyang, S.; Yu, B.; Liu, Y.; Huang, K.; Gong, J.; Zheng, S.; Li, Z.; Li, H.; Jiang, H. PharmMapper server: a web server for potential drug target identification using pharmacophore mapping approach. Nucleic Acids Res 2010, 38, W609-614, https://doi.org/10.1093/nar/gkq300

25. Chitrala, K.N.; Yeguvapalli, S. Computational prediction and analysis of breast cancer targets for 6-methyl1, 3, 8-trichlorodibenzofuran. PLoS One 2014, 9, https://doi.org/10.1371/journal.pone.0109185. 
26. Schneidman-Duhovny, D.; Dror, O.; Inbar, Y.; Nussinov, R.; Wolfson, H.J. PharmaGist: a webserver for ligand-based pharmacophore detection. Nucleic Acids Res 2008, 36, W223-228, https://doi.org/10.1093/nar/gkn187.

27. Starosyla, S.A.; Volynets, G.P.; Bdzhola, V.G.; Golub, A.G.; Protopopov, M.V.; Yarmoluk, S.M. ASK1 pharmacophore model derived from diverse classes of inhibitors. Bioorg Med Chem Lett 2014, 24, 44184423, https://doi.org/10.1016/j.bmcl.2014.08.011.

28. Li, Z.; Wan, H.; Shi, Y.; Ouyang, P. Personal experience with four kinds of chemical structure drawing software: review on ChemDraw, ChemWindow, ISIS/Draw, and ChemSketch. J Chem Inf Comput Sci 2004, 44, 1886-1890, https://doi.org/10.1021/ci049794h

29. Hanwell, M.D; Curtis, D.E; Lonie, D.C.; Vandermeersch, T.; Zurek, E.; Hutchison; G.R. Avogadro: an advanced semantic chemical editor, visualization, and analysis platform. J Cheminform 2012, 4, https://doi.org/10.1186/1758-2946-4-17

30. Morris, G.M.; Huey, R.; Lindstrom, W.; Sanner, M.F.; Belew, R.K.; Goodsel, D.S.; Olson, A. AutoDock4 and AutoDockTools4: Automated docking with selective receptor flexibility. J Comput Chem 2009, 30, 2785-2791, https://doi.org/10.1002/jcc.21256

31. Fedarovich, A.; Djordjevic, K.A.; Swanson, S.M.; Peterson, Y.K.; Nicholas, R.A.; Davies, C. Highthroughput screening for novel inhibitors of Neisseria gonorrhoeae penicillin-binding protein 2. PLoS One 2012, 7, https://doi.org/10.1371/journal.pone.0044918.

32. Nemmara, V.V.; Dzhekieva, L.; Sarkar, K.S.; Adediran, S.A.; Duez. C.; Nicholas, R.A.; Pratt, R.F. Substrate specificity of low-molecular mass bacterial DD-peptidases. Biochemistry 2011, 50, 10091-10101, https://doi.org/10.1021/bi201326a. 